\title{
UPAYA PENGEMBANGAN DISIPLIN ANAK DENGAN METODE PEMBIASAAN PEMBERIAN KALUNG ANGKA PADA KELOMPOK B3 DI RA AL-JIHAD PADALARANG
}

\author{
Mega Nurmala ${ }^{1}$, Ema Aprianti ${ }^{2}$ \\ ${ }^{1}$ RA Al-Jihad, Padalarang \\ ${ }^{2}$ PG PAUD, IKIP SILIWANGI \\ 1'meganurmala6@gmail.com, ${ }^{2}$ emaaprianti88@gmail.com
}

\begin{abstract}
This study was conducted based on the findings of problems related to the discipline of children in the B3 group at RA Al-Jihad Padalarang. Early observations show that children's discipline is low: coming late to school, fighting for a place when lining up, overtaking each other while waiting in line, letting shoes in the yard, and scrambling bag storage. Based on this, the purpose of this research is to know how the planning, implementation and evaluation of the development of children's discipline through the method of habituation of necklace numbers. The research method used is descriptive, qualitative. The subjects of this study were children of group B3. Techniques and data collection tools using interview techniques, observation, documentation studies and literature studies. From the data obtained, it is known that the method of hiring numerical necklace in developing the children's discipline in B3 group in RA Al-Jihad Padalarang is very effective and well developed and applied, consistent and consistent so that children's discipline develops as expected. The development of discipline through the method of hiring a necklace of numbers is done every day, every child arrives at school, and can be used in everyday activities both in the classroom and outside the classroom and using indicators of developmental achievements that exist in early childhood discipline theories.
\end{abstract}

Keywords: Discipline, Method of Nominal Numerical Chaining

\begin{abstract}
Abstrak
Penelitianinidilakukanberdasarkantemuanmasalah yang terkaitdengankedisiplinananakpadakelompok B3 di RA AlJihad Padalarang. Berdasarkaobservasiawalmenunjukanrendahnyakedisiplinananakseperti: terlambatdatangkesekolah, berebuttempatsaatberbaris, salingmendahuluisaatmengantri, membiarkansepatu di halaman, danberebuttempatpenyimpanantas.Berdasarkanhaltersebut, yang menjaditujuandaripenelitianiniadalahmengetahuibagaimanaperencanaan, pelaksanaandanevaluasipengembangandisiplinanakmelaluimetodepembiasaanpemberiankalungangka.

Metodepenelitian yang digunakanadalahdeskriptif, berbentukkualitatif. Subjekpenelitianiniadalahanakkelompok B3. Teknikdanalatpengumpulan data menggunakanteknikwawancara, observasi, studidokumentasidanstudiliteratur. Dari data yang diperolehdiketahuibahwametodepembiasaanpemberiankalungangkadalammengembangkandisiplinanakpadakelomp ok B3 di RA Al-Jihad Padalarang, sangatefektifsertadikembangkandanditerapkandenganbaik, konsistendankonsekuensehinggakedisiplinananakberkembangsesuaidengan diharapkan. Pengembangandisiplinmelaluimetodepembiasaanpemberiankalungangkadilakukansetiaphari, setiapanaktiba di sekolah, dandapatdigunakandalamkegiatansehari-haribaik dalamkelasmaupundiluarkelasdanmenggunakanindikatorcapaianperkembangan yang adapadateori-
\end{abstract} teorikedisiplinananakusiadini.

Kata Kunci: Disiplin, MetodePembiasaanPemberiankalungAngka

\section{PENDAHULUAN}

Disiplinmerupakansesuatu menyatudidalamdiriseseorang munculdalampolatingkahlakusehari-hari, munculnyaperilakudisiplinpadaanaktergantungdari yang stimulasi yang diberkanoleh orang dewasaatau yang orang disekitarnyabdrkaitandenganadanyaaturanaturan yang harus di taatiolehanak. 


\section{Vol.1_ No.2 L Maret 2018}

Adapunkepatuhanatauketaatanpadaperaturante rsebutadalahsepertihalnyamerapikandanmengemba likanmainanpadatempatnya, antriuntukbergantianbermainatauantrimakan, tidakberlariandidalamkelas, dudukpadatempatya, menyimpankembalimaiananpadatempatnyadan lain-lain.

Penanamandisiplinpadaanakusiadinidapatdilak ukandalamprilakusehari-hari, yang padagilirannyaakanmenjadikebiasaanhidup.

Pembiasaanmerupakanbagianpentingdalamtahappe nalarandimanaanakmula-

mulamengembangkanketerampilanhidupnya.

Pembiasaanpemberiankalungangkamerupakan pembiasaan yang dilakukansetiapharipadasaatanakdatang/tibadisekol ahdenganmemberikankalungangkapadaanak.

Untukmenumbuhkembangkankedisiplinanpadaana kdapatdilakukanmelalui program yang telahdirencanakansebelumnyaolehpihaksekolah yang dalamhalini, guru menjadifasilitatoruntukmenstimulasinya.

Untuk memecahkan permasalahan di atas, maka melalui diskusi dengan guru kelas B3 di RA Al-Jihad, disepakati untuk menggunakan metode pembiasaan dengan pemberian kalung angka sebagai salah satu alternatif pemecahan masalah. Berdasarkan latar belakang diatas maka peneliti mengambil judul penelitian tentang "Upaya Pengembangan Disiplin Anak Melalui Metode Pembiasaan Pemberian Kalung Angka Pada Kelompok B3 Di RA Al-Jihad Padalarang."

\section{KAJIAN TEORI DAN METODE}

Disiplin merupakan proses bimbingan yang bertujuan menanamkan pola prilaku tertentu, kebiasaan-kebiasaan tertentu atau membentuk manusia dengan ciri-ciri tertentu, yang meningkatkan kualitas mental dan moral.

Menurut(Wiyani, 2013. Hlm. 8) perilaku disiplin pada anak usia dini adalah suatu pengendalian diri terhadap perilaku anak usia 0-6 tahun dalam berprilaku sesuai dengan ketentuan yang berlaku bisa berupa tatanan nilai, norma, dan tata tertib di rumah dan di sekolah. Penanaman sikap disiplin pada anak di lingkungan sekolah dapat berupa menyimpan sepatu pada rak sepatu, menyimpan tas pada loker masing-masing, membereskan tempat mainannya, masuk kelas tepat waktu, membuang sampah pada tempatnya,berbaris dengan rapi sebelum masuk ke kelas.

Mendidik kedisiplinan pada anak merupakan proses yang dilakukan oleh orang tua dan guru sepanjang waktu. Oleh karena itu, disiplin harus dilakukan secara kontinu dan istiqamah.

Ali Imron(Novan, 2013. Hlm 47) mengungkapkan bahsa setidaknya ada tiga jenis disiplin, antara lain disiplin yang dibangun berdasarkan konsep otoritarian, disiplin yang dibangun berdasarkan konsep permissive, dan disiplin yang dibangun berdasarkan konsep kebebasan yang bertanggung jawab.

1. Disiplin Otoritarian

Dalam disiplin otoritarian, peraturan dibuat sangat ketat dan rinci. Orang yang berada dalam lingkungan disiplin ini diminta untuk mematuhi dan menaati peraturan yang telah disusun dan berlaku ditempat itu.

2. Disiplin Permissive

Dalam disiplin ini seseorang dibiarkan bertindak menurut keinginannya. Kemudian dibebaskan untuk mengambil keputusan sendiri dan bertindak sesuai dengan keputusan yang diambilnya itu.

\section{Disiplin Demokratis}

Menurut (Wiyani, 2013. Hlm. 48)penerapan jenis disiplin berdasarkan konsep kebebadan dan tanggung jawab (demokratis) kepada anak usia dini sangatlah tepat. Hal ini disebabkan dalam penerapannya terdapat nilai-nilai demokratis, yaitu menekankan hak anak untuk menentukan pilihannya dalam berbuat dan kewajiban anak untuk menerima konsekuensi dari perbuatannya.

Disiplin sekolah bila diterapkan dan dikembangkan dengan baik, yang dilakukan secara konsisten dan konsekuen akan berdampak positif bagi kehidupan anak dimasa yang akan datang. Dalam upaya mengambangkan prilaku disiplin dapat dilakukan melalui kegiatan pembiasaan.

Pembiasaan dapat diartikan sebagai sebuah cara yang dapat dilakukan untuk membiasakan anak didik berfikir, bersikap dan bertindak sesuai dengan tuntutan ajaran islam. Pembiasaan dinilai efektif jika penerapannya dilakukan terhadap peserta didik yang berusia kecil.

Menurut Abdullah Nasir Ulwan (Zubaedi, 2017. Hlm. 377), metode pembiasaan adalah upaya 


\section{JURNAL CERIA}

ISSN : 2614-6347 (Print) 2614-4107 (Online)

Vol.1 No.2 | Maret 2018

yang praktis dalam pembentukan karakter anak. Dalam buku metodologi pengajaran agama dikatakan bahwa metode pebiasaan adalah cara yang dilakukan dalam pembentukan akhlak dan rohani yang memerlukan latihan yang kontinu setiap hari.

Kebiasaan baik terbentuk dan berkembang melalui proses pendidikan yang baik, misalnya kebiasaan dalam berkomunikasi, pengaturan dan penggunaan waktu secara tepat, bersikap baik dan tepat, memilih permainan dan menggunakan saran dengan tepat. Anak perlu dibiasakan sejak dini untuk mengatur dan menggunakan waktu secara tepat, agar kelak bisa menjadi orang disiplin dan bertanggung jawab. Pembiasaan sebaiknya ditanamkan dari hal-hal kecil dan yang mudah dilakukan oleh anak usia dini. Agar pembiasaan dapat segera tercapai dan hasilnya baik, setidaknya ada 4 syarat yang harus dipenuhi, oleh pendidik PAUD dalam menggunakan metode pembiasaan ini, yaitu:

1. Pembiasaan mulai dilakukan sejak anak berada pada masa bayi, dimana masa tersebut merupakan masa yang paling tepat untuk menerapkan metode ini. Kebiasaan positif maupun kebiasaan negative itu akan muncul sesuai dengan lingkungan yang membentuknya.

2. Pembiasaan hendaknya dilakukan secara beranjut, teratur, dan terprogram atau terjadwal sehingga pada akhirnya akan terbentuk sebuah kebiasaan yang utuh, permanen dan konsisten.

3. Pembiasaan sebaiknya diawali secara ketat, konsisten, dan tegas.

4. Pembiasaan yang semula bersifat mekanis, sebaiknya secara berangsur-angsur berubah menjadi kebiasaan yang tidak verbalistik dan menjadi kebiasaan yang disertai dengan kata hati anak itu sendiri seiring dengan bertambahnya usia anak. (Najib, 2016. Hlm. 136)

Metode penelitian yang digunakan adalah deskriptif, berbentuk kualitatif.Menurut Sugiyono, (2011. Hlm. 9) metode penelitian kualitatif adalah metode penelitian yang berlandaskan pada filsafat postpositivisme, digunakan untuk meneliti pada kondisi obyek yang alamiah, (sebagai lawannya adalah eksperimen) dimana penelitian adalah sebagai insrumen kunci, teknik pengumpulan data dilakukan secara triangulasi (gabungan), analisis data bersifat induktif/ kualitatif, dan hasil penelitian kualitatif lebih menekankan makna dari pada generalisasi.Subjek penelitian ini adalah anak kelompok B3 yang berjumlah 16 siswa.Teknik dan alat pengumpulan data menggunakan teknik wawancara, observasi, studi dokumentasi dan studi literatur.

\section{HASIL PENELITIAN DAN PEMBAHASAN \\ 1. Perencanaan Upaya Pengembangan Disiplin Anak Melalui Metode Pembiasaan Pemberian Kalung Angka Pada Kelpmpok B3 Di RA Al-Jihad Padalarang}

Berdasarkan penelitian dilapangan, kegiatan perencanaaan pengembagan disiplin anak melalui metode pembiasaan pemberian kalung angka pada kelompok B3 di RA Al- Jihad Padalarang diterapkan dengan berbagai kegiatan yang sistematis. Adapun hasil perencanaan yang telah dilaksanakan, maka diperoleh data sebagai berikut:

Merumuskan tujuan upaya pengembangan disiplin anak melalui metode pembiasaan pemberian kalung angka pada kelompok B3 di RA Al-Jihad Padalarang.

Berdasarkan penelitian dengan diterapkannya metode pembiasaan pemberian kalung angka pada kelompok B3 di RA Al- Jihad Padalarang bertujuan agar anak terbiasa memiliki perilaku disiplin seperti memotivasi anak agar datang tepat waktu, menyimpan sepatu dan tas pada tempatnya, tertib saat berbaris dan anti, cuci tangan sebelum makan. Hal ini terkait dengan pendapat Wiyani (2013: 8) bahwa perilaku disiplin pada anak usia dini adalah suatu pengendalian diri terhadap perilaku anak usia 0-6 tahun dalam berprilaku sesuai dengan ketentuan yang berlaku bisa berupa tatanan nilai, norma, dan tata tertib di rumah dan di sekolah. Penanaman perilaku disiplin pada anak di dalam kelas berupa menyimpan sepatu pada rak sepatu, menyimpan tas pada loker masing-masing, membereskan tempat mainannya, masuk kelas tepat waktu, membuang sampah pada tempatnya,berbaris dengan rapi sebelum masuk ke kelas.

Berdasarkan Penelitian Dilapangan, SOP pembiasaan pemberian kalung angka sebagai berikut: pertama penyambutan anak, kedua anak mengisi daftar hadir yang disediakan guru, ketiga 


\section{JURNAL CERIA}

ISSN : 2614-6347 (Print) 2614-4107 (Online)

\section{Vol.1_No.2 L Maret 2018}

menggambil nomor (angka) urutan kedatangan, keempat anak menyimpan sepatu pada loker yang ditempel angka dan menyimpannya menurut angka yang diperolehnya, kelima anak masuk kedalam kelas kemudia menyimpan tas ditempat yang di tempel angka juga. Sehingga anak mencari loker/ tempat yang sesuai dengan kalung angka. Kalung angka dipakai selama di sekolah, dan pendidik bisa memanfaatkannya dalam berbagai kegiatan. Keenam kalung angka dilepas ketika bersalaman pulang.

Adapun indikator tingkat pencapaian dan upaya pengembangan disiplin melalui metode pembiasaan pemberian kalung angka yang telah dirumuskan guru berdasarkan indikator aspek nilaki agama dan moral berdasarkan pereturan pemerintah No. 137 tahun 2013.

Indikator Tingkat Pencapaian

Perkembangan Upaya Pengembangan Disiplin Anak Melalui Metode Pembiasaan Pemberian Kalung Angka Pada Kelompok B3 Di RA AlJihad Padalarang

\begin{tabular}{|l|l|l|l|l|l|}
\hline \multirow{2}{*}{ No. } & \multicolumn{1}{|c|}{ Indikator } & \multicolumn{3}{|c|}{ Penilaian } \\
\hline & & BM & MM & BSH & BSB \\
\hline 1. & $\begin{array}{l}\text { Datang Tepat } \\
\text { Waktu }\end{array}$ & & & & \\
\hline 2. & $\begin{array}{l}\text { Mengikiti } \\
\text { Aturan } \\
\text { Permainan }\end{array}$ & & & & \\
\hline 3. & $\begin{array}{l}\text { Menyimpan } \\
\text { Sepatu Pada } \\
\text { Tempatnya }\end{array}$ & & & & \\
\hline 4. & $\begin{array}{l}\text { Mengambil } \\
\text { Sepatu Dengan } \\
\text { Tertib }\end{array}$ & & & & \\
\hline 5. & $\begin{array}{l}\text { Menyimpan } \\
\text { Tas Pada } \\
\text { Tempatnya }\end{array}$ & & & & \\
\hline 6. & $\begin{array}{l}\text { Mengambil Tas } \\
\text { Dengan Tertib }\end{array}$ & & & & \\
\hline 7. & Berbaris & & & \\
\hline 8. & $\begin{array}{l}\text { Mengan Tertib } \\
\text { Perilaku Yang } \\
\text { Dapat } \\
\text { Menyesuaikan } \\
\text { Diri }\end{array}$ & & & & \\
\hline 9. & $\begin{array}{l}\text { Mengambil } \\
\text { Barang Dari } \\
\text { Tempatnya }\end{array}$ & & & & \\
\hline 10. & $\begin{array}{l}\text { Mengembalikan } \\
\text { Barang Pada }\end{array}$ & & & & \\
\hline
\end{tabular}

\begin{tabular}{|c|l|l|l|l|l|}
\hline & Tempatnya & & & & \\
\hline 11. & $\begin{array}{l}\text { Melaksanakan } \\
\text { Kegiatan } \\
\text { Sendiri }\end{array}$ & & & & \\
\hline 12. & $\begin{array}{l}\text { Sabar } \\
\text { Menunggu } \\
\text { Giliran }\end{array}$ & & & & \\
\hline 13. & $\begin{array}{l}\text { Bertanggung } \\
\text { Jawab } \\
\text { Terhadap Tugas }\end{array}$ & & & & \\
\hline 14. & $\begin{array}{l}\text { Mengakui } \\
\text { Keunggulan } \\
\text { Orang Lain }\end{array}$ & & & & \\
\hline 15. & $\begin{array}{l}\text { Cuci Tangan } \\
\text { Sebelum } \\
\text { Makan }\end{array}$ & & & & \\
\hline 16. & $\begin{array}{l}\text { Cuci Tangan } \\
\text { Sesudah Makan }\end{array}$ & & & & \\
\hline 17. & $\begin{array}{l}\text { Tolong } \\
\text { Menolong }\end{array}$ & & & & \\
& $\begin{array}{l}\text { Dalam } \\
\text { Merapihkan } \\
\text { Diri }\end{array}$ & & & & \\
\hline 18. & $\begin{array}{l}\text { Tolong } \\
\text { Menolong } \\
\text { Merapihkan } \\
\text { Teman }\end{array}$ & & & & \\
\hline
\end{tabular}

Media yang akandigunakandalampengembangandisiplinmelalui metodepembiasaanpemberiankalungangkainidianta ranya format isiandaftarhadiranakdankalungangka. Kalungangkadibuatdaribahankertas yang diberiangkasejumlahanaktiapkelas. Angka di prinkemudiandilaminating, selanjutnyadiberitaliuntukdipakai di leher.

Sosialisasidengan orang tuasebagaiupayauntukmensukseskanpengembanga ndisiplinpadaanak di sekolah. Karenahaliniakanberkaitandengankeberangkatanan akkesekolah.

PembuatanRencanaPelaksanaanPembelajaran Harian (RPPH), yang akan d terapkanpadaanakdalamupayapengembangandisipli nanakmelaluimetodepembiasaanpemberiankalunga ngkapadakelompok B3 di RA Al-Jihad Padalarang.

Peraturandalampembiasaanpemberiankalunga ngka yang diterapkanoleh guru merupakanpengembangandaritatatertibsekolahdana turankelasdibuatsupayamasalah yang terjadidikelasberkurang, dananakakanmendapatkonsekuensi/hukumanjikam 
elanggar, hukumanataukonsekuensidibuatolehanakdandisepa katibersamamisalnyaanak melanggarharusmakansendiri.

Penerapanunsur-unsurkedisiplinan yang dilakukanoleh yang guru tersebutmerupakanunsurpokokuntuterwujudnyaseb uahdisiplindisekolah. Hal inisamadenganpendapat yang di kemukakanolehWiyani (2013: 43-45) bahwadisiplinsangatpentingartinyabagianak. Oleh karena itu, disiplin harus dibentuk secara terusmenerus kepada anak. Ada tiga unsur kedisiplinan, antara lain kebiasaan, peraturan dan hukuman.

\section{Pelaksanaan Upaya Pengembangan Disiplin Anak Pada Kelompok B3 Di RA Al-Jihad Padalarang}

Pelaksanaan upaya pengembangan disiplin anak melalui metode pembiasaan kalung angka pada kelompok B3 di RA Al-Jihad Padalarang merupakan tindakan untuk memulai, memotivasi dan mengarahkan serta mempengaruhi anak untuk berkelakuan disiplin, mengerjakan tugas-tugas sekolah dan mentaati peraturan yang ada di sekolah. Untuk mencapai tujuan disiplin anak. Hal ini sesuai dengan pendapat yang yang dikemukankan oleh (Tulus, 2004. Hlm. 33)bahwa disiplin adalah mengikuti dan mentaati peraturan, nilai dan hukum yang berlaku, disiplin dapat terwujud oleh empat kekuatan, yakni mengikuti dan mentaati aturan, adanya kesadaran diri hasil proses pendidikan, hukuman dalam rangka pendidikan.

Berdasarkan hasil penelitian, bahwa guru sudah melakukan melakukan peran dengan semestinya dalam pengembangan disiplin anak melalui metode pembiasaan pemberian kalung angka. Guru menerapkan jenis-jenis disiplin untuk mengembangkan disiplin anak melalui metode pembiasaan pemberian kalung angka yaitu dengan mengkombinasikan antara demokratis dan otoriter. Hal ini sesuai dengan pendapat Ali Imron (Wiyani, 2004: 47) mengatakan bahwa terdapat tiga jenis penanaman disiplin pada anak yaitu secara otoriterial, permissive, dan demokratis. Mengatakan bahwa masing-masing jenis mempunyai kelebihan, cara disiplin yang dibangun berdasarkan konsep otoriterian guru bisa dengan bebas memberikan perintah yang positif kepada anak. Cara disiplin permissive guru cendrung memberikan kebebasan kepada anak untuk berbuat apa saja yang diinginkannya tanpa bimbingan orang tua. Cara demokratis memberikan memberikan kebebasan seluas-luasnya kepada anak untuk berbuat apapun tetapi konsekuensi dari perbuatannya itu haruslah anak yang menanggungnya.

Pada awalnya kegiatan ini dilakukan terasa berat oleh anak tetapi lama kelamaan kegiatan ini menjadi suatu kebiasaan yang baik menuju kearah disiplin karena dlakukan cer terus menerus. Hal ini sesuai dengan pendapat yang dikemukakan oleh Maman Rachman (Tulus, 2004. Hlm. 50)mengatakan bahwa pembiasaan disiplin disekolah akan mempunyai pengaruh positif bagi kehidupan siswa dimasa datang.

Dalam upaya mengembangkan disiplin anak melalui metode pembiasaan pemberian kalung angka guru menerapkan langkah-langkah pembiasaan agar mempermudah guru dalam apa yang diinginkannya. Ada empat syarat yang harus dipenuhi oleh pendidik paud dalam menggunakan metode pembiasaan yang dikemukakan oleh (Najib, 2016. Hl. 136) bahwa: 1) pembiasaan dilakukan sejak anak usia dini, 2) pembiasaan hendaknya dilakukan secara berlanjut, teratur dan terprogram, 3) pembiasaan hendaknya diawali secara ketat, konsisten dan tegas, 4) pembiasaan yang semula bersifat mekanis, sebaiknya secara berangsur-angsur berubah menjadi kebiasaan.

Guru RA Al-Jihad sudah menggunakan langkah-langkah yang harus dipenuhi dalam menggunakan metode pembiasaan pemberiasaan yang dikatakan Najib dkk dalam mengembangkan disiplin anak melalui metode pembiasaan pemberian kalung angka.

Langkah pertama Guru RA Al-Jihad menggunakan metode pembiasaan pemberian kalung angka pada kelompok B3 dalam mengembangkan disiplin sejak usia dini. Langkah kedua, metode pembiasaan pemberian kalung angka dilakukan secara teratur setiap hari, ketika anak tiba disekolah yang akan digunakan selama anak berada di sekolah yang di mana nomor yang ada dalam kalung angka akan digunakan dalam kegiatan. Langkah ketiga, metode pebiasaan pemberian kalung angka dalam mengembangkan disiplin anak dilakukan secara konsisten dan tegas 


\section{JURNAL CERIA}

ISSN : 2614-6347 (Print) 2614-4107 (Online)

Vol.1 No.2 | Maret 2018

bahwa anak yang pertama tiba di sekolah akan memperoleh kalung angka nomor 1 dan berada di barisan pertama ketika berbaris dan antri. Guru konsisten dengan peraturan yang telah dibuat, tidak memberikan kesempatan kepada anak untuk melanggar kebiasaan yang telah ditanamkan.

\section{Evaluasi upaya pengembangan disiplin anak melalui metode pembiasaan pemberian kalung angka pada kelompok B3 di RA Al-Jihad Padalarang.}

Evaluasi pengembangan disiplin anak dilakukan untuk menilai keberhasilan pelaksanaan dalam pengembangan disiplin anak melalui metode pembiasaan pemberian kalung angkapada kelompok B3 di RA al-jihad padalarang.

Penilaian dalam pengembangan disiplin anak melalui metode pembiasaan pemberian kalung angka di RA Al-Jihad dilakukan oleh guru, karena guru memliki tugas sebagai penilai. Penilaian tidak dilakukan oleh satu guru, tetapi dapat melibatkan guru lain yang biasa bersama anak dalam keseharian anak belajar.

Evalusai dilakukan untuk mengetahui sejauh mana keberhasilan upaya pengembangan disiplin anak melalui metode pembiasaan pemberian kalung angka yang telah guru terapkan. Hal ini sesuai dengan pendapat yang dikemukakan oleh Ali (2010: 9) bahwa tujuan evaluasi adalah untuk mengetahui sejauh mana keefektipan pelaksanaan layanan program stimulasi dan pencapaian hasil yang diperoleh setiap anak.

Hasil penilaian pengembangan disiplin anak melalui metode pembiasaan pemberian kalung angka dilaporkan kepada pihak-pihak yang terkait, yang kemudian akan dilakukan pengkajian untuk menemukan kelebihan dan kekurangan serta sebagai factor pendukung dan penghambat dalam pengembangan disiplin anak melalui metode pembiasaan pemberian kalung angka pada kelompok B3 di RA Al-Jihad Padalarang. Hasil kajian tersebut dijadikan sebagai bahan untuk melakukan upaya perbaikan terhadap pengembangan disiplin anak melalui pembiasaan pemberian kalung angka di RA Al-Jihad pada tahun berikutnya.

\section{KESIMPULAN}

Berdasarkan analisis dan hasil pembahasan sebelumnya, maka peneliti dapat simpulkan mengenai upaya pengembangan disiplin anak melalui metode pembiasaan pemberian kalung angka pada kelompok B3 di RA Al-Jihad Padalarang dilakukan melalui tiga proses yaitu:

1. Perencanaan upaya pengembangan disiplina anak melalui metode pembiasaan pemberian kalung angka dimulai dengan merumusan tujuan, merumusan SOP (Standar Oprasional Prosedur) pembiasaan pemberian kalung angka, merumuskan indikator tingkat pencapaian, media yang digunakan dalam pengembangan disiplin anak melalui metode pembiasaan pemberian kalung angka, mensosialisasikannya kepada orang tua sebagai upaya untuk mensukseskan pengembangan disiplin pada anak di sekolah, merencanakan RPPH dalam penerapan pengembangan disiplin melalui metode pembiasaan pemberian kalung angka.

2. Pelaksanaan upaya pengembangan disiplin anak melalui metode pemberian kalung angka pada kelompok B3 di RA Al-Jihad Padalarang, dilakukan setiap hari, setiap anak tiba di sekolah dan dipakai selama anak berada disekolah mulai dari datang sampai anak pulang. Pelaksanaan upaya pengembangan disiplin anak melalui metode pembiasaan pemberian kalung angka terdapat dalam kegiatan pembelajaran dan pembiasaan. Yang dilakukan dalam kegiatan sehari-hari baik di dalam kelas maupun diluar kelas dan menggunakan indikator capaian perkembangan yang ada pada teori-teori kedisiplinan anak usia dini.

3. Evaluasi pengembangan disiplin anak melalui metode pembiasaan pemberian kalung angka dilakukan oleh guru, Penilaian tidak dilakukan oleh satu guru, tetapi dapat melibatkan guru lain yang biasa bersama anak dalam keseharian anak belajar menggunakan lembar pantauan anak di lingkungan sekolah. Proses penilaian dilakukan melalui pengamatan terhadap anak. Saat anak melakukan kegiatan, guru dapat mengamati segala hal yang dilakukan anak, termasuk ekspresi wajah, dan gerakan.

Dari data yang diperoleh diketahui bahwa metode pembiasaan pemberian kalung angka dalam mengembangkan disiplin anak pada 


\section{JURNAL CERIA}

ISSN : 2614-6347 (Print) 2614-4107 (Online)

Vol.1 No.2 L Maret 2018

kelompok B3 di RA Al-Jihad Padalarang, sangat efektif serta dikembangkan dan diterapkan dengan baik, konsisten dan konsekuen sehingga kedisiplinan anak berkembang sesuai dengan yang diharapkan.

\section{SARAN}

1. Bagi Kepala Sekolah

Diharapkan terus memantau dan membina guru untuk menjadi teladan yang baik bagi anak dan memperbaharui peraturan di sekolah sesuai kebutuhan anak

2. Bagi Guru

a. Guru hendaknya memotivasi dan selalu membimbing anak agar selalu berperilaku disiplin.

b. Guru agar lebih konsisten terhadap anak demi tercapainya tujuan dalam pengembangan disiplin pada anak.

c. Hendaknya guru dengan orangtua bekerjasama dalam mengembangkan disiplin anak.

3. Bagi Peneliti

Diharapkan peneliti manjadi teladan yang baik dan dapat menerapkan metode pembiasaan pemberian kalung angka secara konsisten dalam mengembangkan disiplin anak.

4. Bagi Anak

Diharapkan anak dapat selalu menjaga disiplin dalam mematuhi peraturan yang diterapkan di sekolah.

\section{DAFTAR PUSTAKA}

Ali, N. (2010). Evaluasi Pembelajaran Untuk Anak Usia Dini. Bandung. Universitas Pendidikan Indonesia

Diklat HIMPAUDI. (2013). Kota Cimahi

Direktorat. (2011). Disiplin Pada Anak. Jakarta

Direktorat. (2007). Pedoman Pembalajaran Bidang Pembiasaan Di Taman KanakKanak. Jakarta

Najib. (2016). Manajemen Strategik Pendidikan Karakter Bagi Anak Usia Dini. Yogyakarta: Gava Media.
Novan, W. (2013). Bina Karakter Anak Usia Dini. Yogyakarta: Ar-Ruzz Media.

Sugiyono. (2011). Metode Penelitian Kuantitatifkualitatif Dan $R \& D$. Bandung: Alfabeta.

Tulus, T. (2004). Peran Disiplin Pada Perilaku Dan Prestasi Siswa. Jakarta: Grasino.

Zubaedi. (2017). Strategi Taktis Pendidikan Karakter. Depok: Raja Grafindo Persada. 